\title{
TECHNICAL THEORY AND VERIFICATION OF FLOWING WATER DIVERSION IN NEW RAINWATER DISCHARGE CHAMBER
}

\author{
Shuhei ODA1, Kohei ODA² and Shinji ARAO3 \\ ${ }^{1}$ Member of JSCE, Waken Design Office Inc. (34-11 Shinjuku 1-chome, Shinjuku-ku, Tokyo 160-0022, Japan) \\ E-mail: s-oda@wsnet.co.jp \\ ${ }^{2}$ Member of JSCE, Waken Design Office Inc. (34-11 Shinjuku 1-chome, Shinjuku-ku, Tokyo 160-0022, Japan) \\ E-mail:kh-oda@wsnet.co.jp \\ ${ }^{3}$ Member of JSCE, Professor, Dept. of Civil and Environmental Eng., National Institute of Technology, \\ Matsue College (14-4, Nishi Ikuma-cho, Matsue-shi Shimane 690-8518, Japan) \\ E-mail: arao@matsue-ct.jp
}

\begin{abstract}
The combined sewer improvement projects dealt with in advanced sewer areas have issues in flowing water splitting accuracy in a rainwater discharge chamber, which is an important point in the combined sewer system. It is also pointed out that this measure has low improvement effect as well as complicated maintenance and management. The flowing water splitting function is made by organically combining the hydraulic phenomena of an overflow weir and an orifice. While the conventional technology directly controls the flow rate by splitting one time, this study proposes indirect control of the flow rate of suppressing water level fluctuation by splitting multiple times. This study has proven validity from the viewpoint of practical management through numerical analysis of the splitting phenomenon and careful examination of the data of a hydraulic model experiment to verify the technical theories of the conventional direct control and the new indirect control in flowing water splitting. The result of this study has confirmed the improvement effect where an error in the $45 \%$ level in the conventional technology can be reduced to $3 \%$ or less by the technology used in this study in the numerical analysis and the hydraulic model experiment focusing on the excessive interception error. It has also shown that the immediate issues in the combined sewer can be solved.
\end{abstract}

Key Words : combined sewer system, diversion chamber, intercepting problem

\section{INTRODUCTION}

(1) Present situation and issues of the rainwater discharge chamber function

The current measure in the splitting of the sewage flow rate in the rainwater discharge chamber is illustrated in Fig. $\mathbf{1}^{1), 2)}$. The standard equipment is a mechanism where a flow path matching a planned intercepted sewage flow rate being the base of a sewer plan is composed of an overflow weir and an intercepting culvert. The sewage flow rate exceeding the planned intercepted sewage flow rate runs over the overflow weir and is split into effluence water areas (public water areas such as rivers and so on) and thus, excess sewage is eliminated.

Conventional improvement measures of the rainwater discharge chamber are illustrated in Fig. $\mathbf{2}^{3)}$. Their basic structures are mechanisms to control the sewage flow rate flowing into the intercepting culvert and to enhance the function of the overflow weir. In this conventional system, however, the water level rises in the regulating tank. Therefore, at the time of heavy rain, the intercepted sewage flow rate reaches the planned intercepted flow rate several times ${ }^{3)}$ and the combined sewer system collapses, bringing about problems such as intercept-

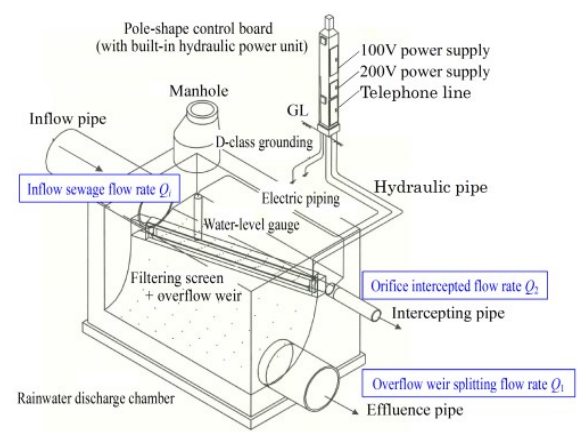

Fig. 1 Conceptual view of rainwater discharge chamber. 
Orifice type

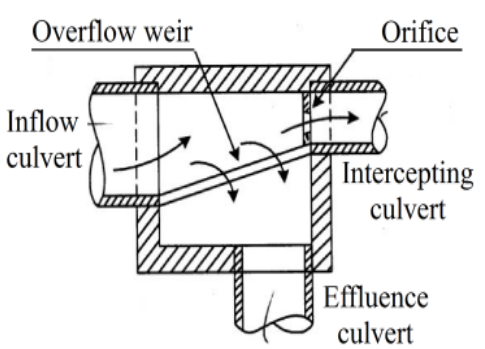

Vortex valve type

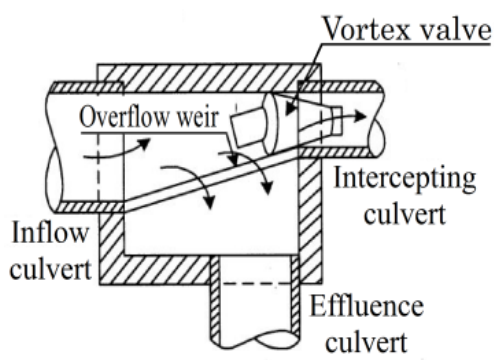

Falling water division type

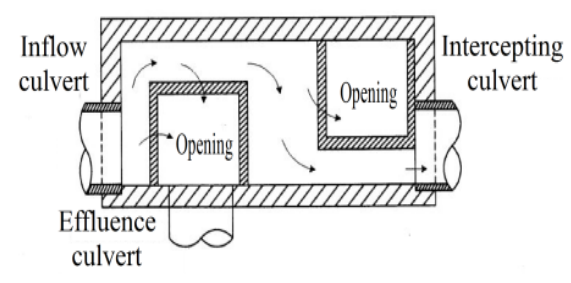

Fig. 2 Conceptual view of intercepting and splitting function improvement measure for conventional standard rainwater discharge chamber (plane view).

ing and combining flow and untreated water effluence ${ }^{1), 3}$. Besides, it is difficult to provide additional floating impurity-eliminating equipment ${ }^{4)}$ and there are many issues in solving those problems in the narrow rainwater discharge space.

\section{(2) Objective of this study}

The objective of this study is to develop a new diversion facility capable of keeping constant the intercepted water flow rate from the rainwater discharge chamber even during heavy rain. This is based on the flowing water splitting theory in the overflow weir and the orifice using the conventional hydraulic knowledge. To achieve the objective of this study, first of all, an on-site facility in a project case is employed as a verification model, and the interception error ((actual intercepted flow rate planned intercepted flow rate)/planned intercepted flow rate) on the full-scale is found by numerical analysis using the conventional technology and the newly developed flowing water splitting theory used in the proposed technology of this study. Second, the validity of the numerical analysis result is proved by comparing the hydraulic model experimental result using a scale-down model of the on-site facility and the numerical analysis result. Lastly, the usefulness of the newly developed diversion facility will be described through a schematic design in the project case.

\section{FLOWING WATER SPLITTING THE- ORY OF THIS STUDY}

\section{(1) Basic theory of flowing water splitting char- acteristics}

The flowing water splitting function of the rainwater discharge chamber is to keep constant (fix) the sewage flow rate down into the intercepting culvert. This is done by setting the overflow weir crest height of the water level in the regulating tank to correspond to the planned intercepted sewage flow rate. The inflow sewage flow rate exceeding the overflow weir crest height is then split into the effluence water areas and eliminated.
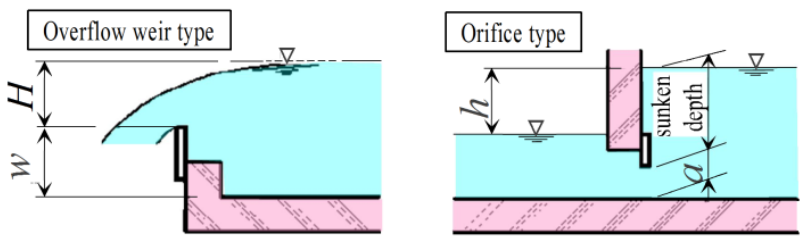

Fig. 3 Conceptual views of flow states at overflow weir and orifice.

The basic theory of the flowing water splitting is based on the hydraulic phenomena of the overflow weir and the orifice illustrated in Fig. $\mathbf{3}^{5), 6)}$.

The overflow flow rate $Q_{1}\left(\mathrm{~m}^{3} / \mathrm{s}\right)$ at the overflow weir is calculated by eq. (1).

$$
Q_{1}=C_{1} \cdot B \cdot H^{3 / 2}
$$

where $C_{1}$ is the flow rate coefficient (practical general value 1.8$), B$ is the overflow weir width (m), $H$ is the overflow water depth (m), and $W$ is the overflow weir crest height.

The hydraulic characteristics of the flowing water splitting in the rainwater discharge chamber are practically determined to be the same as the hydraulic characteristics in a front overflow state because the intercepted sewage flow rate with respect to the inflow sewage flow rate is as small as $1 / 20$ to $1 / 100$. The flow velocity toward the orifice in an overflow weir section in the regulating tank is also very low.

The flow rate $Q_{2}\left(\mathrm{~m}^{3} / \mathrm{s}\right)$ out of the orifice is calculated by eq. (2).

$$
Q_{2}=C_{2} \cdot a \cdot(2 \cdot g \cdot h)^{1 / 2}
$$

where $C_{2}$ is the flow rate coefficient (general value $0.6), a$ is the orifice hole area $\left(\mathrm{m}^{2}\right), h$ is the head difference $(\mathrm{m})$, and the general value of a submergence depth of an inflow hole opening required for the formation of an orifice phenomenon is 1.3 times or more than the orifice hole opening height. Note that $C_{2}$ relates to Reynolds number so that an outflow hole cross-sectional area reduces more with higher flow velocity due to an increase in $h$, and converges to about 0.6 in many cases. Further, $C_{2}$ is 
slightly smaller in a submerge-type orifice than in effluence in air, and is not supposed to be different between completely submerged large and small orifices in terms of hydraulics ${ }^{7,8)}$. In the flowing water splitting theory of this study, the general value of 0.6 is employed for $C_{2}$, based on the Technical Standards (draft $)^{5), 6)}$ in public work projects in the practical viewpoint similarly to the overflow weir type.

\section{(2) Splitting theory for inflow sewage flow rate} and improvement measures

a) Bases of the flowing water splitting theory

A flow rate increase $\left(\Delta Q_{1}\right)$ in the overflow weir section increases by $3 / 2$ power of the increased overflow water depth and the flow rate coefficient increases by approximately 1.8 ; whereas a flow rate increase $\left(\Delta Q_{2}\right)$ at the orifice increases by $1 / 2$ power of the increased head difference and the flow rate coefficient increases by approximately 2.66 including $(2 \mathrm{~g})^{1 / 2}$, but an influence of water level rising in the same regulating tank on $\Delta Q_{2}$ is extremely small as compared with $\Delta Q_{1}$.

For the rainwater discharge chamber function, the above-described hydraulic phenomena are organically combined. The utilization of hydraulic phenomenon of the orifice type for the intercepted sewage route to fix the flow rate, and the utilization of hydraulic phenomenon of the overflow weir type for the effluent sewage route to quickly eliminate the increased flow rate into effluence water areas, are the bases of the flowing water splitting theory.

b) Conventional improvement measure and newly proposed improvement measure

The conventional rainwater discharge chamber improvement measure is based on the basic theory, and controls the flow-down rate into the intercepting culvert illustrated in Fig. 2 and increases the splitting and eliminating flow rate by enhancing the overflow weir function, thus directly controlling the target flow rate. However, the hydraulic phenomenon mentioned here is followed by an increase in water level in the regulating tank immediately before the intercepting culvert, which necessarily increases the orifice flow rate and therefore causes the failure to sufficiently control the intercepting and splitting error.

The rainwater discharge chamber improvement measure in this study (hereinafter described as the new technology) aims to fix the water level in the final regulating tank at the downstream end even when the inflow flow rate into the rainwater discharge chamber is increased. This is done by partitioning the rainwater discharge space with walls to create several regulating tank spaces. The combined overflow weirs and orifices control sequentially the levels of the rainwater discharge in each of the regulating tanks, and indirectly controls the target flow rate of the water levels (refer to Fig. 4).

\section{VERIFICATION OF THE TECHNICAL THEORY BY NUMERICAL ANALYSIS}

\section{(1) Items to be verified and a determination method}

a) Items to be verified and a verification method

As for the items to be verified, this study focuses on the interception error for its object, and numerically analyzes and compares one-time splitting in the conventional technology and multiple-time splitting in the new technology to quantitatively verify their improvement effects.

\section{b) Setting of a verification model}

As the model to be verified, the actual rainwater discharge chamber equipment is taken up here. As the improvement measure in the conventional technology, one-time splitting is performed by the orifice hole control method, and the orifice hole throttling in the verification model is set up to $1 / 2$ (an aperture ratio of $71 \%$ ) in terms of cross-sectional area ratio, in consideration of management of transported dust. On the other hand, in the multiple-time splitting method, the verification model in the new technology, the number of sections of the regulating tank is set to 4 , in consideration of facility management. The constituent dimensions of the facilities are listed in Table 1.

Table 1 Main constituent dimension table.

\begin{tabular}{|c|c|c|c|}
\hline & Overflow weir width (m) & Orifice diameter ${ }^{1}$ \\
\hline \multicolumn{2}{|c|}{ Conventional technology } & $13.00 \mathrm{~m} \times 1$ weir & $\Phi 0.35 \mathrm{~m}, \Phi 0.286 \mathrm{~m}, \Phi 0.247 \mathrm{~m}$ \\
\hline \multirow{3}{*}{ New technology } & 2-tanks type & $6.50 \mathrm{~m} \times 2$ weirs & Same as above \\
\hline & 3-tanks type & $4.33 \mathrm{~m} \times 3$ weirs & Same as above \\
\hline & 4-tanks type & $3.25 \mathrm{~m} \times 4$ weirs & Same as above \\
\hline
\end{tabular}

$*^{1} \Phi 0.35 \mathrm{~m}$ is used as a standard, $\Phi 0.286 \mathrm{~m}$ is employed for an area ratio of $2 / 3$, and $\Phi 0.247 \mathrm{~m}$ is employed for an area ratio of $1 / 2$, according to existing facility.

Fig. 4 Conceptual view of new technology (three regulating tanks). 


\section{c) Numerical analysis method and the focus range of improvement effect}

As expressed in eq. (3), the sewage flow rate $Q_{i}$ $\left(\mathrm{m}^{3} / \mathrm{s}\right)$ flowing into the rainwater discharge chamber from the confluent pipe is found in the overflow flow rate $Q_{1}\left(\mathrm{~m}^{3} / \mathrm{s}\right)$ from the overflow weir and the intercepted flow rate $Q_{2}\left(\mathrm{~m}^{3} / \mathrm{s}\right)$ from the orifice.

$$
Q_{i}=Q_{1}+Q_{2}
$$

The numerical analysis method calculates a head difference $\left(h_{0}\right)$ in the regulating tank by eq. (2) with the intercepted flow rate $\left(Q_{2}\right)$ regarded as the planned intercepted flow rate $\left(Q_{0}\right)$, and sets the head difference $\left(h_{0}\right)$ as the overflow weir crest height of the regulating tank. Thereafter, calculations using eqs. (1), (2) and (3) are performed in succession. In Table 6 which well be described later in Chapter 5, $Q_{1}$ and $Q_{i}$ corresponding to the increase in $Q_{2}$ are calculated by additional calculation. In comparing the improvement effects in interception error, the effects are compared with the comparison data made dimensionless to avoid the influence of the sewage flow rate scale.

The vertical axis in Fig. 5 indicates the index value (times) of the inflow sewage flow rate into the rainwater discharge chamber and is given in eq. (4). The horizontal axis indicates the index value $(\%)$ of the excess in the planned intercepted sewage flow rate $\left(Q_{2}\right)$ and is given in eq. (5).

Sewage flow rate ratio $=\frac{\operatorname{inflow} \operatorname{rate}\left(Q_{i}\right)}{\text { planned intercepted flow rate }\left(Q_{0}\right)}$
Interception error (\%)

$$
=\frac{\text { excessive intercepted flow } \operatorname{rate}\left(Q_{2}-Q_{0}\right)}{\text { planned intercepted flow } \operatorname{rate}\left(Q_{0}\right)} \times 100
$$

Though the sewage flow rate ratio (vertical axis) tends to decrease in the project case and the trend of the environmental improvement ${ }^{9)}$, the evaluation focus range of the interception error is set to a range of a sewage flow rate ratio of 20 to 100 times in consideration also of the heavy rain trend in recent years ${ }^{10)}$. The evaluation is made while focusing on a sewage flow rate ratio of 50 times near its intermediate value.

\section{(2) Evaluation of numerical analysis results}

In the numerical analysis results illustrated in Fig 5, the throttling effect of the orifice hole is that the interception error could be improved to $1 / 1.2$ by throttling the hole area to $1 / 2$ of one tank in the conventional technology. This shows that the measure of throttling the orifice hole has a constraint in on-site management of the transported dust, and a reduction of approximately $20 \%$ in interception error is an indication of the improvement effect.

The use of multiple regulating tanks could improve the interception error of one tank in the conventional technology to $1 / 10$ by using two tanks, to $1 / 40$ by using three tanks, and to $1 / 110$ by using four tanks. This shows that the use of multiple regulating tanks improves reduction of interception error by approximately $97 \%$ by using three tanks. This proves that the new technology has an outstanding improvement effect compared to the conventional technology.

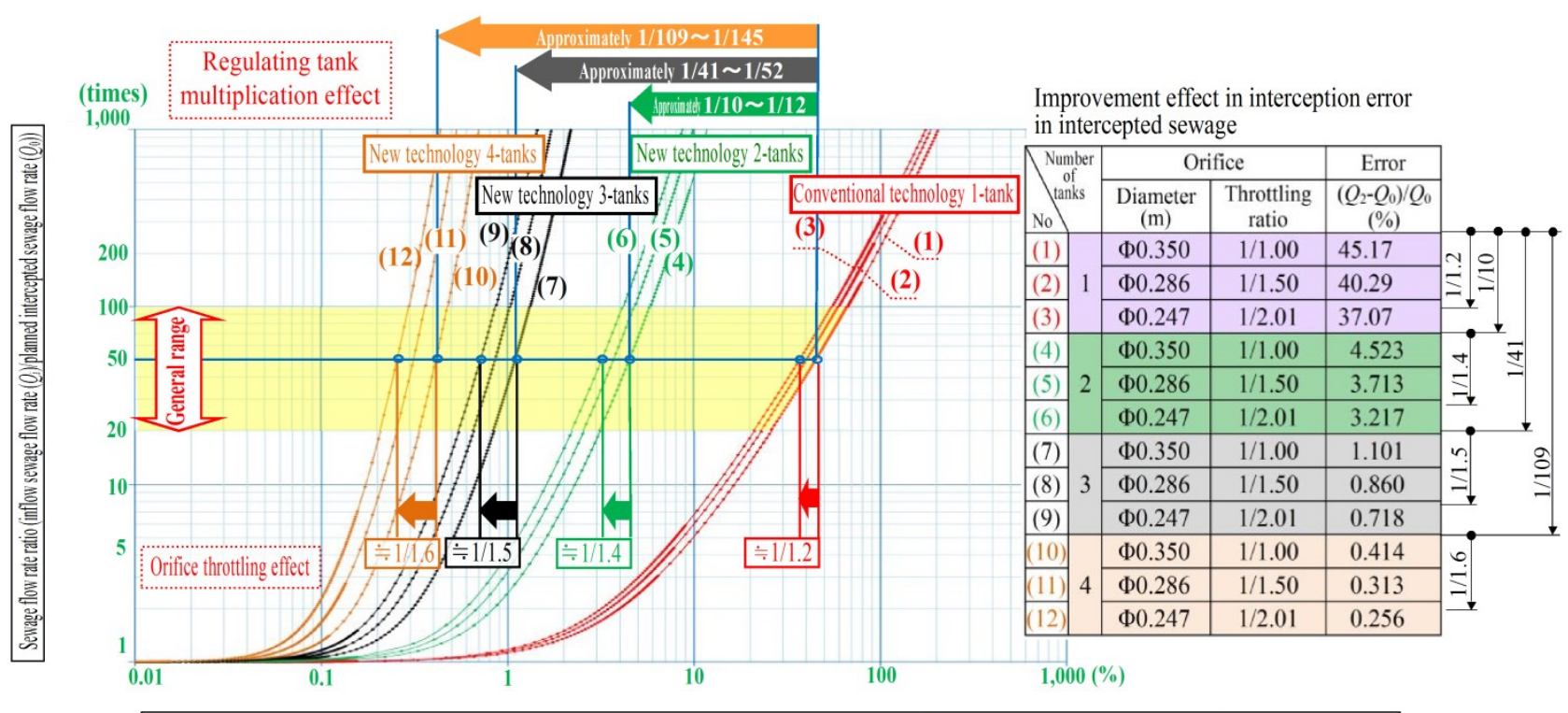

Interception error in intercepted sewage flow rate (excessive intercepted sewage flow rate $\left(Q_{2}-Q_{0}\right)$ planned intercepted sewage flow rate $\left.\left(Q_{0}\right) \times 100\right)$

Fig. 5 Improvement effect in interception error by the new technology (numerical analysis result). 


\section{VERIFICATION OF THE TECHNICAL THEORY IN THE HYDRAULIC MODEL EXPERIMENT}

(1) Objective and dimensions of the hydraulic model experiment

a) Objective of the hydraulic model experiment

From the numerical analysis results in Fig. 5 in Chapter 3, the rainwater discharge chamber function shows that the characteristics of the hydraulic phenomenon is capable of drastically improving the interception accuracy by using multiple regulating tanks. The hydraulic phenomenon is confirmed again by a hydraulic model experiment.

b) Selection of actual model dimensions of a target on site

For verification on site, an actual model composed of one regulating tank having an overflow weir width of $13 \mathrm{~m}$ and an orifice diameter of $\Phi$ $0.35 \mathrm{~m}$ was employed in the conventional technology shown in Table 1 in Chapter 3. A model composed of three successive tanks, each having an overflow weir width of $4.33 \mathrm{~m}$ and an orifice diameter of $\Phi 0.35 \mathrm{~m}$, to match the whole space of the rainwater discharge chamber with the actual model, was employed in the new technology.

c) Selection of model dimensions of targets of the hydraulic experiment

Considering that there is no difference in terms of hydraulics between completely submerged large and small orifices regarding the intercepting and splitting function ${ }^{7)}$, the model of the conventional technology had an overflow weir width set to 0.39 $\mathrm{m}$ (1/33 scale of on-site scale). The characteristics of both the on-site and miniature models were compared based on numerical analysis data on five kinds of temporarily-set orifice diameters listed in Fig. 6. Their similarities were evaluated, and a model size exhibiting the characteristics closest to those of the on-site size was selected.

Similarly, for a model size of the new technology, the model space in the conventional technology was equally divided into three pieces to provide three successive tanks each having an overflow weir width of $0.13 \mathrm{~m}$. Similarities in hydraulic phenomena between both the on-site and miniature models were evaluated by numerical analysis on temporarily-set numerical orifice diameters, and a model size was selected.

\section{d) Selection of a model orifice diameter}

As illustrated in Fig. 6, it is confirmed, in a curve of relation between the sewage flow rate ratio (vertical axis) and the interception error in intercepted sewage flow rate (horizontal axis), that there is extremely high similarity between both the on-site and miniature models and there is no difference between completely submerged large and small orifices in hydraulic phenomenon. From the results in Fig. 6, as a scale-down model size of an on-site dimension of an orifice diameter of $\Phi 0.35 \mathrm{~m}, \Phi 0.01$ $\mathrm{m}$ with highest similarity in the curve is employed.

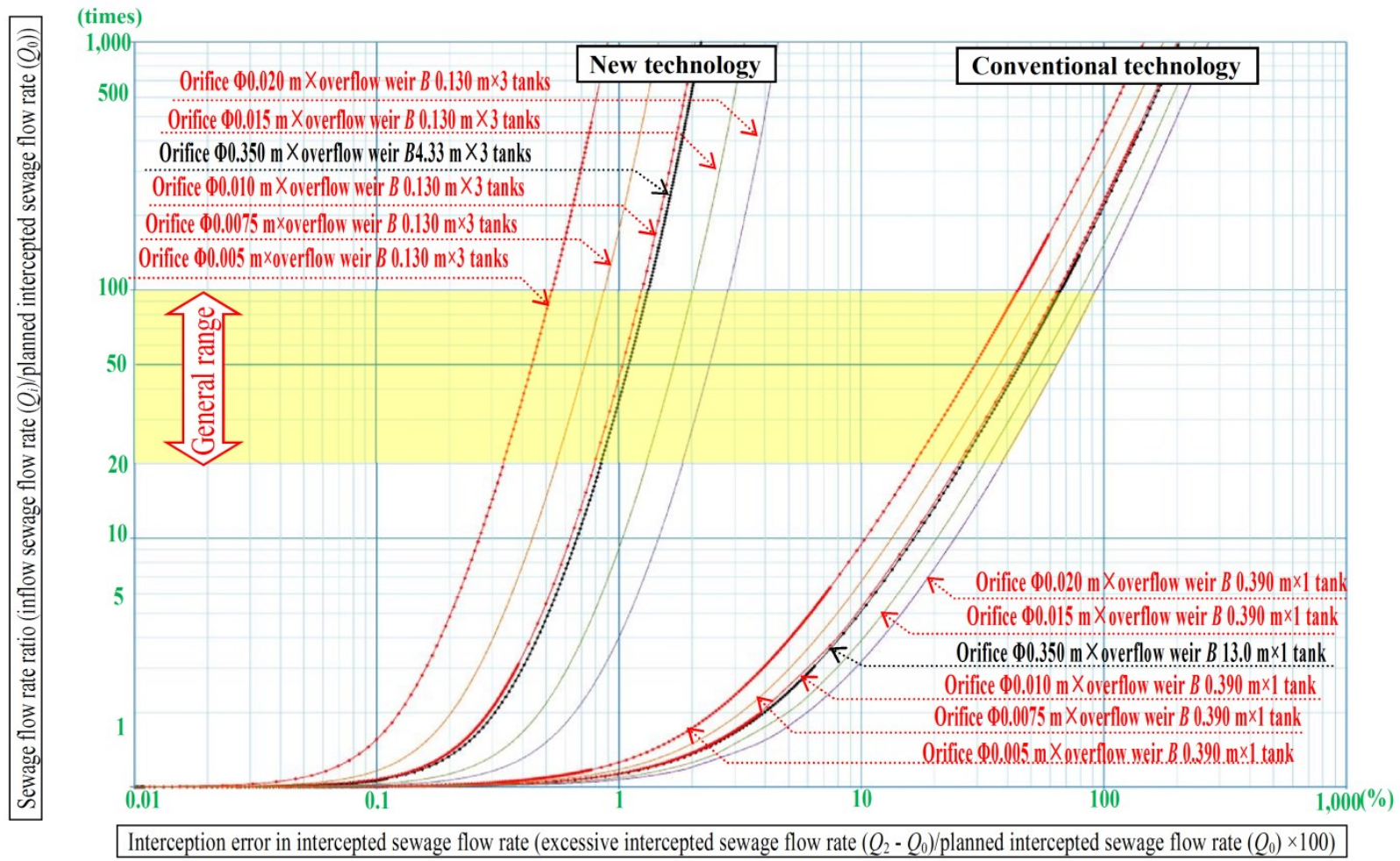

Fig. 6 Selection and determination chart of hydraulic experimental model targeting orifice diameter of $\Phi 0.35 \mathrm{~m}$ in real scale. 
(2) Confirmation of the hydraulic phenomenon in the hydraulic model apparatus

a) Basic configurations of the model apparatuses and functions in experiment and measurement

The experimental apparatuses for the hydraulic models are designed to distribute a supply water flow rate to routes of the overflow weir and the orifice and measure the distributed water flow rates. They are configured as shown in Fig. 7 in the apparatuses of the following systems:

- Outline of an apparatus of a water supply system

In a water supply apparatus from a water source container to the experimental apparatus, a pump water flow rate is confirmed by a sensor and a fixed flow rate of water is pumped up by a regulating valve operation into a calming chamber, where the water is made into an experimental water flow rate by calming the pressure-feeding fluctuation in water supply by a pump, and then supplied to an experimental apparatus system.

- Outline of the apparatuses of experimental systems and experiment conditions

A regulating water tank is composed of an intercepting and splitting apparatus made by combining an overflow weir apparatus with a part of an outer wall cutout and an orifice opened in a partition wall. This apparatus is composed of one regulating tank having an overflow weir width of $0.39 \mathrm{~m}$ and an orifice diameter of $\Phi 0.01 \mathrm{~m}$ in the conventional technology, and is composed of three regulating tanks each having an overflow weir width of $0.13 \mathrm{~m}$ and an orifice diameter of $\Phi 0.01 \mathrm{~m}$ in the new technology. While the overflow weir crest height of the regulating tank connected to an intercepting pipe secures a submergence depth of $0.013 \mathrm{~m}$ of an orifice hole crest, the water flow rate under this hydraulic condition is set to a base flow rate (= planned intercepted sewage flow rate) of the model experiment.

- Measuring method of the experimental water flow rate

Flow rates of water flowing out of the overflow weir and out of the orifice hole are received by containers for individual systems. The weights of the flow rates of distributed water flowing into the containers are measured using platform scales, and the weights are divided by the measuring time to find the outflow rates.

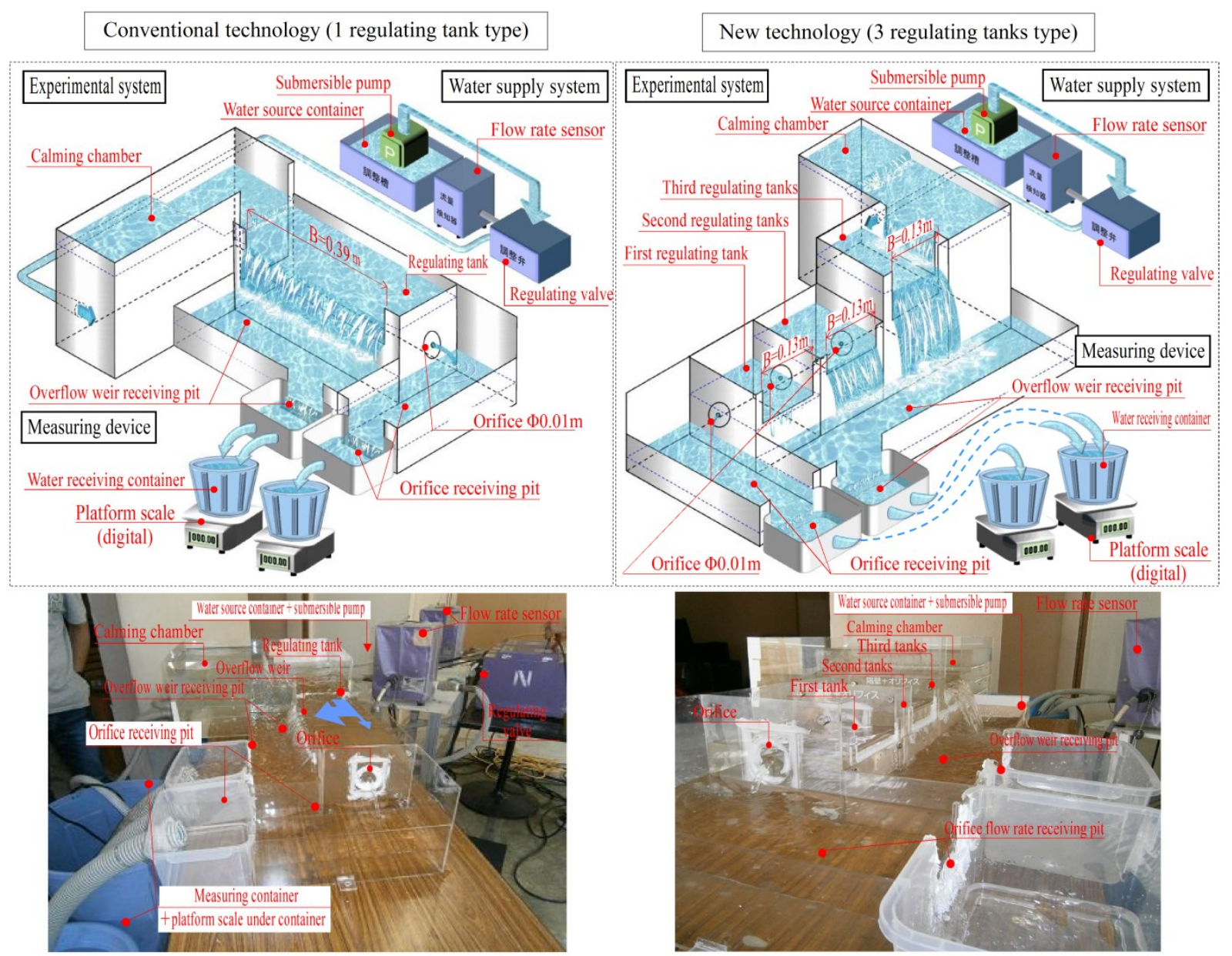

Fig. 7 Experimental equipment configurations and experimental state photographs. 
b) Points of attention in the hydraulic model experiment and measurement data

- Points of attention in the model apparatus

A small-scale experimental model was greatly influenced by surface tension, and therefore a wooden piece was used to stroke the weir crest part so as to eliminate its surface tension. Further, since the unevenness of the pump discharge rate influences the fluctuation in experimental water flow rate, basically, the measuring time was set to 20 seconds for the overflow weir route where the flow rate was large, and the measuring time was set to 1 minute for the orifice route where the flow rate was small, so as to secure the reliability of measurement data.

- Initial phenomenon setting of the new technology difficult to specify the flow rate coefficient

As for the flow rate coefficient when effluence in air and a submerged orifice exist together, it is difficult to previously specify the numerical value. Therefore, in the 3-regulating tanks type, the overflow weir of the downstream first tank was opened, while the overflow weirs of the second tank and the third tank were closed to pass water; the water level there was set as the overflow weir height of the first tank, the overflow crest heights of the second tank and the third tank were specified, and an initial water passing phenomenon (base flow rate) was reproduced.
- Observation findings of the hydraulic experiment and measurement data.

Experimental states are shown in Fig. 7, and experimental measurement data in the conventional technology (one regulating tank) and the new technology (three regulating tanks) are listed in Table 2 and Table 3, respectively. Comparing Table 2 and Table 3, it is found that the interception error was greatly decreased in the new technology and even when the inflow water flow rate was increased, the intercepted flow rate $Q_{2}$ became almost constant. The flying distance of the outflow water vein from the orifice increased with an increase in supply water flow rate in the conventional technology, but rarely changed in the new technology. Therefore, the hydraulic phenomena supporting the measurement data were also visually confirmed.

\section{(3) Analysis and evaluation of the hydraulic ex- perimental results}

Figure 8 is created from the numerical analysis results in Fig. 6 and the experimental data in Table 2 and Table 3, and comprehensive determination is made based on both results.

\section{a) Analysis and evaluation of the measurement data}

The numerical analysis results illustrated in Fig. 8 are results obtained with the flow rate coefficients $\left(C_{1}, C_{2}\right)$ of the overflow weir and the orifice fixed,

Table 2 Interception error measurement table of conventional technology (one regulating tank).

\begin{tabular}{|c|c|c|c|c|c|c|c|c|c|c|c|c|c|c|c|}
\hline & \multicolumn{6}{|c|}{ Overflow flow rate $Q_{1}$} & \multicolumn{4}{|c|}{ Intercepted flow rate $Q_{2}$} & \multicolumn{2}{|c|}{$\begin{array}{l}\text { Sewage flow rate ratio } \\
\text { (times) }\end{array}$} & $\begin{array}{c}\text { Interception } \\
\text { error }(\%)\end{array}$ & \multirow{2}{*}{ Remark } \\
\hline & & \multicolumn{2}{|c|}{ Start weight $(\mathrm{kg})$} & \multicolumn{2}{|c|}{ End weight (kg) } & \multirow[t]{3}{*}{$\begin{array}{l}\text { Time } \\
(\mathrm{sec})\end{array}$} & \multirow[t]{3}{*}{$\begin{array}{c}\text { Flow rate } \\
(1 / \mathrm{sec})\end{array}$} & \multirow{2}{*}{$\begin{array}{r}\begin{array}{r}\text { Start } \\
(\mathrm{kg})\end{array} \\
1.00 \\
\end{array}$} & \multirow{2}{*}{$\begin{array}{l}\begin{array}{l}\text { End } \\
(\mathrm{kg})\end{array} \\
4.60 \\
\end{array}$} & \multirow{2}{*}{$\begin{array}{c}\begin{array}{c}\text { Time } \\
(\mathrm{sec})\end{array} \\
120 \\
\end{array}$} & \multirow{2}{*}{$\begin{array}{c}\begin{array}{c}\text { Flow rate } \\
(1 / \mathrm{sec})\end{array} \\
0.03000 \\
\end{array}$} & \multirow[t]{3}{*}{$Q_{i}=Q_{1}+Q_{2}$} & \multirow[t]{3}{*}{$Q_{i} / Q_{0}$} & \multirow[t]{3}{*}{$\left(Q_{2}-Q_{0}\right) / Q_{0}$} & \\
\hline \multirow{4}{*}{ 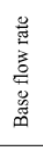 } & & & & & & & & & & & & & & & \\
\hline & & & & & & & & 1.00 & 4.60 & 120 & 0.03000 & & & & \\
\hline & & & & & & & & 1.00 & 4.58 & 120 & 0.02983 & Overall mean & & & Planned intercepted \\
\hline & & & & & & & & 1.00 & 4.59 & 120 & 0.02992 & $0.0299=Q_{0}$ & & & sewage flow rate \\
\hline \multirow{22}{*}{ 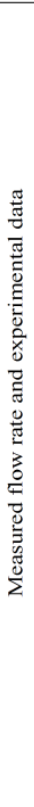 } & \multirow{2}{*}{ (1) } & 13.0 & \multirow{2}{*}{26.8} & 20.8 & \multirow{2}{*}{42.0} & \multirow{2}{*}{10} & \multirow{2}{*}{1.5200} & \multirow{2}{*}{1.50} & \multirow{2}{*}{4.00} & \multirow{2}{*}{60} & \multirow{2}{*}{0.0417} & \multirow{2}{*}{1.5617} & 5223 & 3946 & Two apparatuses \\
\hline & & 13.8 & & 21.2 & & & & & & & & & 52.23 & 39.40 & operated \\
\hline & & 12.0 & & 19.0 & & & & & & & & & & & \\
\hline & (2) & 11.8 & 23.8 & 20.0 & 39.0 & 10 & 1.5200 & 1.50 & 4.40 & 60 & 0.0483 & 1.5683 & 52.45 & 61.54 & Same as above \\
\hline & (3) & 16.0 & 270 & 31.0 & 580 & 20 & 15500 & 4.40 & & 60 & 0.0425 & 15925 & & & \\
\hline & (3) & 11.0 & 27.0 & 27.0 & 58.0 & 20 & 1.5500 & 4.40 & 0.95 & 60 & 0.0425 & 1.5925 & 53.26 & 42.14 & Same as above \\
\hline & $(4)$ & 17.5 & 205 & 32.0 & 600 & 20 & 15250 & 265 & 5.35 & 60 & 00450 & 15700 & 5251 & 5050 & Same as above \\
\hline & (4) & 12.0 & 28.0 & 28.0 & 00.0 & 20 & 1.5250 & 2.05 & 5.30 & 00 & 0.0450 & $1.5 / 00$ & 52.51 & 50.50 & Same as above \\
\hline & (5) & 10.6 & 166 & 17.8 & 320 & 20 & 07700 & 705 & 030 & 60 & 00375 & 08075 & 2701 & 2542 & One apparatus \\
\hline & (ग) & 6.0 & 10,0 & 14.2 & & & & & & & & & 21.01 & 25.42 & operated \\
\hline & $(6)$ & 12.0 & 240 & 19.0 & 392 & 20 & 07600 & 315 & 538 & 60 & 00372 & 07972 & 2666 & 2441 & Same as above \\
\hline & (6) & 12.0 & 24.0 & 20.2 & 39.2 & 20 & 0.1600 & 3.15 & 5.38 & 60 & 0.0372 & 0.7972 & 26.66 & 24.41 & Same as above \\
\hline & (7) & 13.2 & 202 & 19.9 & 351 & 20 & 07450 & 190 & 4.20 & 60 & 00383 & 07833 & 2620 & 2809 & Same as above \\
\hline & (t) & 7.0 & 20.2 & 15.2 & 35.1 & 20 & 0.1430 & 1.90 & 4.20 & 00 & 0.0383 & 0.1833 & 20.20 & 28.09 & Same as aoove \\
\hline & $(8)$ & 13.5 & 278 & 20.5 & 410 & 20 & 07050 & 210 & 430 & 60 & 00367 & 07417 & 2481 & 2274 & Same as above, \\
\hline & (0) & 14.3 & 21.0 & 21.4 & 41.9 & 20 & 0.1050 & 2.10 & 4.20 & 00 & 0.0501 & 0.1417 & 24.01 & 22.14 & slightly throttled \\
\hline & (9) & 11.0 & 178 & 27.2 & 50.4 & 60 & 0.5433 & 120 & 330 & 60 & 0.0350 & 0.5783 & 1934 & 1706 & Same as above, \\
\hline & (9) & 6.8 & 17.8 & 23.2 & 50.4 & 60 & 0.5453 & 1.20 & 3.30 & 60 & 0.0350 & $0.5 / 83$ & 19.34 & 17.00 & throttled \\
\hline & (10) & 16.7 & 292 & 32.6 & 612 & 60 & 05333 & 615 & 825 & 60 & 00350 & 0.5683 & 1901 & 1706 & Same as above \\
\hline & (I0) & 12.5 & 29.2 & 28.6 & 01.2 & 00 & 0.5333 & 0.10 & 8.25 & 00 & 0.0350 & 0.5083 & 19.01 & 17.00 & Same as above \\
\hline & (1) & 16.9 & 308 & 33.5 & 6 & 6 & 05483 & 450 & 670 & 60 & 00367 & 05850 & 1057 & 2274 & Same as above \\
\hline & (II) & 13.9 & 50.0 & 30.2 & 05.1 & 00 & 0.0405 & 4.50 & 0.70 & 00 & 0.0501 & 0.5050 & 19.57 & 22.14 & Salne as aove \\
\hline
\end{tabular}


Table 3 Interception error measurement table of new technology (three regulating tanks).

\begin{tabular}{|c|c|c|c|c|c|c|c|c|c|c|c|c|c|c|c|}
\hline & \multicolumn{6}{|c|}{ Overflow flow rate $Q_{1}$} & \multicolumn{4}{|c|}{ Intercepted flow rate $Q_{2}$} & \multicolumn{2}{|c|}{$\begin{array}{c}\text { Sewage flow rate ratio } \\
\text { (times) }\end{array}$} & $\begin{array}{c}\text { Interception } \\
\text { error }(\%)\end{array}$ & \multirow{2}{*}{ Remark } \\
\hline & & \multicolumn{2}{|c|}{ Start weight $(\mathrm{kg})$} & \multicolumn{2}{|c|}{ End weight $(\mathrm{kg})$} & \multirow[t]{3}{*}{$\begin{array}{l}\text { Time } \\
(\mathrm{sec})\end{array}$} & \multirow[t]{3}{*}{$\begin{array}{c}\text { Flow rate } \\
(1 / \mathrm{sec})\end{array}$} & \multirow{2}{*}{$\begin{array}{c}\text { Start } \\
(\mathrm{kg})\end{array}$} & \multirow{2}{*}{$\begin{array}{l}\text { End } \\
(\mathrm{kg})\end{array}$} & \multirow{2}{*}{$\begin{array}{c}\text { Time } \\
(\mathrm{sec})\end{array}$} & \multirow{2}{*}{$\begin{array}{c}\begin{array}{c}\text { Flow rat } \\
(1 / \mathrm{sec})\end{array} \\
0.02917\end{array}$} & \multirow[t]{3}{*}{$Q_{i}=Q_{1}+Q_{2}$} & \multirow[t]{3}{*}{$Q_{i} / Q_{0}$} & \multirow[t]{3}{*}{$\left(Q_{2}-Q_{0}\right) / Q_{0}$} & \\
\hline & & & & & & & & & & & & & & & \\
\hline बूँ & & & & & & & & 1.30 & 3.06 & 60 & 0.02933 & & & & \\
\hline$\sum_{\mathscr{n}}^{\circ}$ & & & & & & & & 3.50 & 5.22 & 60 & 0.02867 & Overall mean & & & Planned intercepted \\
\hline & & & & & & & & 1.00 & 2.73 & 60 & 0.02883 & $0.0290=Q_{0}$ & & & sewage flow rate \\
\hline \multirow{24}{*}{ 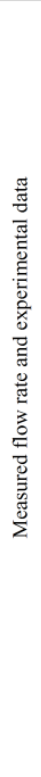 } & \multirow{2}{*}{ (1) } & 14.8 & \multirow{2}{*}{32.3} & 34.0 & \multirow{2}{*}{70.0} & \multirow{2}{*}{20} & \multirow{2}{*}{1.8850} & \multirow{2}{*}{4.80} & \multirow{2}{*}{6.58} & \multirow{2}{*}{60} & \multirow{2}{*}{0.0297} & 1.9147 & 66.02 & 2.41 & Two apparatuses \\
\hline & & 17.5 & & 36.0 & & & & & & & & & & 2.71 & operated \\
\hline & & 11.0 & 26.0 & 29.5 & 62.0 & 20 & 1.8000 & 4.40 & 6.20 & 60 & 0.0300 & 1.8300 & 63.10 & 3.45 & Same as above \\
\hline & (2) & 15.0 & 20.0 & 32.5 & 02.0 & 20 & 1.0000 & 4.40 & 0.20 & 00 & 0.0500 & 1.0500 & 03.10 & $0.4 \mathrm{~J}$ & Same as aoove \\
\hline & (3) & 15.0 & 32.8 & 34.0 & 68.9 & 20 & 1.8050 & 2.20 & 3.98 & 60 & 0.0297 & 1.8347 & 63.27 & 2.41 & Same as above \\
\hline & (3) & 17.8 & & 34.9 & & & & & & & & & & & \\
\hline & (4) & 9.0 & 21.0 & 27.0 & 56.8 & 20 & 1.7900 & 2.50 & 4.27 & 60 & 0.0295 & 1.8195 & 62.74 & 1.72 & Same as above \\
\hline & (4) & 12.0 & & 29.8 & & & & & & & & & & & 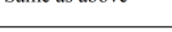 \\
\hline & $(5)$ & 12.5 & 275 & 29.8 & 608 & 20 & 16650 & 5.40 & 718 & 60 & 00297 & 16947 & 58.44 & 241 & Same as above, one \\
\hline & (5) & 15.0 & 21.0 & 31.0 & 00.0 & 20 & 1.0000 & 0.70 & 1.10 & 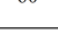 & (1) & (1.08ד & 0.74 & 2.71 & apparatus operated \\
\hline & & 9.6 & 208 & 24.1 & 49.1 & 20 & 14150 & 3.20 & 500 & 60 & 0.0300 & 1.4450 & 49.83 & 345 & Same as above \\
\hline & (6) & 11.2 & 20.0 & 25.0 & & & & & & & & & & & \\
\hline & (7) & 9.0 & 20.2 & 16.8 & 35.8 & 20 & 0.7800 & 3.20 & 4.98 & 60 & 0.0297 & 0.8097 & 27.92 & 2.41 & One apparatus \\
\hline & (t) & 11.2 & & 19.0 & & & & & & & & & & & operated \\
\hline & & 7.8 & 17.6 & 15.7 & 33.2 & 20 & 0.7800 & 2.45 & 4.23 & 60 & 0.0297 & 0.8097 & 27.92 & 2.41 & Same as above \\
\hline & (8) & 9.8 & & 17.5 & & & & & & & & & & & \\
\hline & & 8.7 & 187 & 16.2 & 340 & 20 & 07650 & 3.90 & 568 & 60 & 0.0297 & 07947 & 2740 & 241 & Same as above \\
\hline & (9) & 10.0 & 10.1 & 17.8 & 34.0 & 20 & 0.1050 & 3.90 & 3.00 & 00 & 0.0291 & 0.1941 & 27.40 & 2.41 & Dame as above \\
\hline & & 8.0 & 188 & 16.0 & 341 & 20 & 07650 & 317 & 497 & 60 & 00300 & 07950 & 2741 & 345 & Same as above \\
\hline & (10) & 10.8 & 10.0 & 18.1 & 34.1 & 20 & 0.1050 & 3.17 & 4.91 & 00 & 0.0000 & 0.1950 & 21.41 & 3.45 & Sante as above \\
\hline & & 7.8 & 178 & 11.2 & 241 & 20 & 03150 & 205 & 3.84 & 60 & 0.0298 & 03448 & 1189 & 276 & Same as above, \\
\hline & (11) & 10.0 & 17.0 & 12.9 & 2.1. & 20 & & 2.00 & (1) & 年 & 0.020 & & 1.0. & 2.70 & throttled \\
\hline & & 8.5 & 18.4 & 11.6 & 24.6 & 20 & 0.3100 & 1.50 & 3.28 & 60 & 0.0297 & 0.3397 & 11.71 & 2.41 & Same as above \\
\hline & (12) & 9.9 & & 13.0 & 24.0 & & & & & & & & & & \\
\hline
\end{tabular}

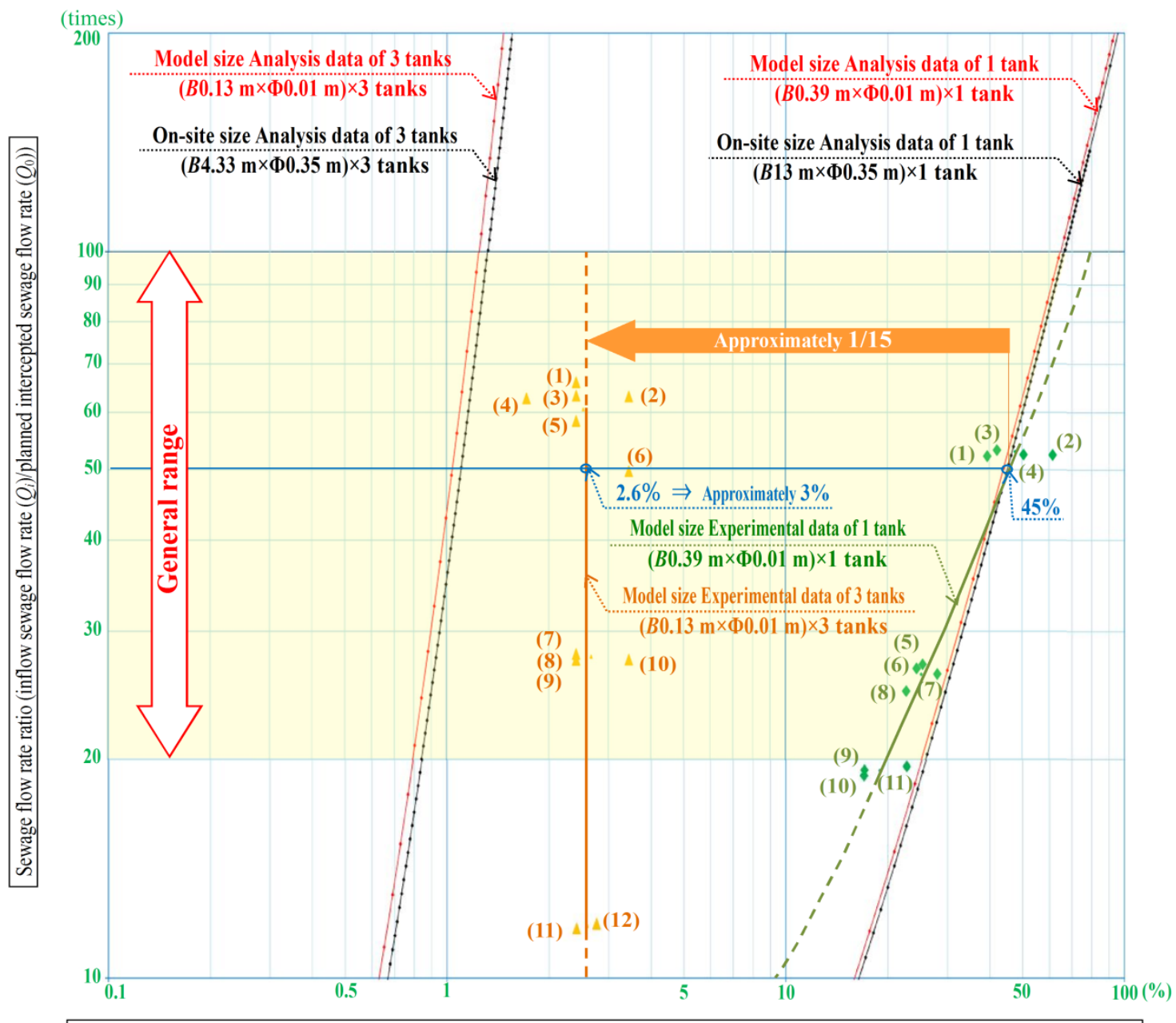

Interception error in intercepted sewage flow rate (excessive intercepted sewage flow rate $\left(Q_{2}-Q_{0}\right) /$ planned intercepted sewage flow rate $\left.\left(Q_{0}\right) \times 100\right)$

Fig. 8 Comparison between hydraulic model experimental result and numerical analysis result. 
and are predicted to have a difference from the results obtained in the hydraulic model experiment. The theory proposed by this study is to keep constant the water level in the final regulating tank at the downstream end by using multiple regulating tanks to fix the intercepted flow rate, and provide a higher effect with a higher inflow sewage flow rate as illustrated in Fig. 5 to sharply decrease the interception error. The result shows that a curve representing its characteristics becomes upright. Comparing the experimental results with the numerical analysis results illustrated in Fig. 8, in the conventional technology (one regulating tank), the inclination of the relation curve obtained from the experimental value becomes slightly gentler than that of the analysis value when the sewage flow rate ratio becomes smaller; the interception error, however, almost matches the numerical analysis data. On the other hand, in the new technology (three regulating tanks), the interception error is near $2.4 \%$ to $3.4 \%$, and the interception error becomes constant irrespective of the sewage flow rate ratio, showing that the multiplication of regulating tanks offers superior improvement effects.

Considering the hydraulic condition set here and a measurement limit in the hydraulic model experiment, Fig. 8 can be evaluated to have obtained the experimental data reproducing the theory proposed by this study on the safe side in terms of practice. Note that from the approximation characteristics between the numerical analysis result and the experimental result in the conventional technology (one regulating tank), an actual site where the target flow rate is large is expected to have an improvement effect in interception error close to the analysis data also in the new technology (three regulating tanks).

\section{b) Evaluation at a sewage flow rate ratio of 50} times

The actual case in Table 1 is a plan using Table 4 as the plan conditions, with the objective of bringing the planned intercepted sewage flow rate $\left(Q_{0}\right)$ to three times $\left(3 Q_{a}\right)$ the planned wastewater flow rate $\left(Q_{a}\right)$ at present, and to $6 Q_{a}$ or more, to halve the number of times of overflow in the rainwater discharge chamber in the combined sewer improvement project. Accordingly, in the actual case, the

Table 4 Plan condition list.

\begin{tabular}{|l|l|}
\hline Planned wastewater flow rate & $Q_{a}=0.0200 \mathrm{~m}^{3} / \mathrm{s}$ \\
\hline Planned intercepted sewage flow rate & $Q_{0}=0.1243 \mathrm{~m}^{3} / \mathrm{s} \quad\left(6.215 \times Q_{a}\right) *^{2}$ \\
\hline Planned rainwater flow rate & $Q_{r}=3.9153 \mathrm{~m}^{3} / \mathrm{s}($ Plan scale: $1 / 3)$ \\
\hline Planned sewage flow rate & $Q_{\max }=3.9353 \mathrm{~m}^{3} / \mathrm{s}$ \\
\hline Excessive intercepted flow rate upper limit & $\begin{array}{l}50 \% \text { of } Q_{0} \\
(\text { Set by water blowout accident reproduction analysis })\end{array}$ \\
*2: $\begin{array}{l}Q_{0}=3 Q_{a} \text { in conventional plan } \quad \therefore \text { Sewage flow rate ratio } \cong 66 \text { times } \\
Q_{0}=6.2 Q_{a} \text { in combined improvement plan } \quad \therefore \text { Sewage flow rate ratio } \cong 32 \text { times }\end{array}$
\end{tabular}

present sewage flow rate ratio of 66 times was brought to 32 times, but evaluation was made using 50 times as a general value in this study.

Focusing on the interception error of a sewage flow rate ratio of 50 times in the hydraulic experimental data in Fig. 8, the interception error in intercepted sewage flow rate was about $45 \%$ in one regulating tank and was about $3 \%$ or less in three regulating tanks in the new technology, resulting in increasing the interception accuracy of approximately 15 times, so that the outstanding improvement effect of the new technology was confirmed also in the hydraulic experiment.

\section{REPRODUCTION VERIFICATION IN A PROJECT CASE}

\section{(1) Plan conditions of a project case}

The combined sewer improvement project in $\mathrm{Y}$ City, K Prefecture in this case decided the plan conditions in Table 4 by halving the number of overflow times in the rainwater discharge chamber in an upper level plan and by a fast flash measure. For verification in the project case, a constraint condition of an excessive intercepted flow rate upper limit was added to the above for pipe line accident countermeasure in heavy rain in the past fiscal year.

\section{(2) Rainwater discharge chamber equipment to be investigated}

Referring to Chapter 1(1) and Chapter 3(2), the rainwater discharge chamber improvement plans to be investigated in this paragraph employed the orifice hole throttling measure and the overflow weir length extending measure from the conventional technology and employed the 3-regulating tanks method from the new technology, using their facility specifications organized in Table 5, and embodied structure forms in Fig. 9 and Fig. 10. Note that for important project investments in the project plans, roughly estimated investment scales of the respective improvement plans, divided into the civil engineering work and the machine and electrical equipment, are listed in Table 7.

Table 5 Rainwater discharge chamber improvement plan list.

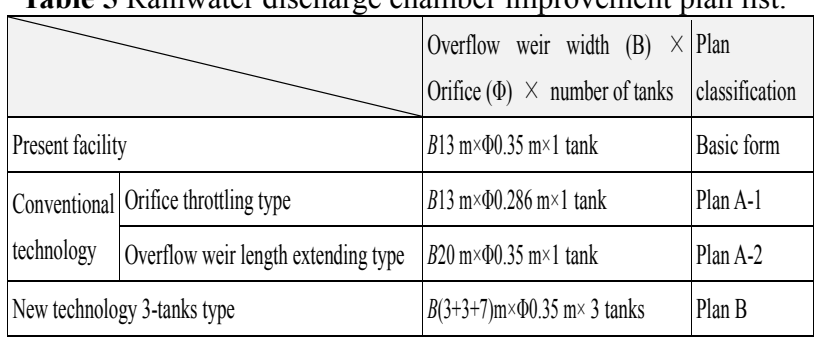



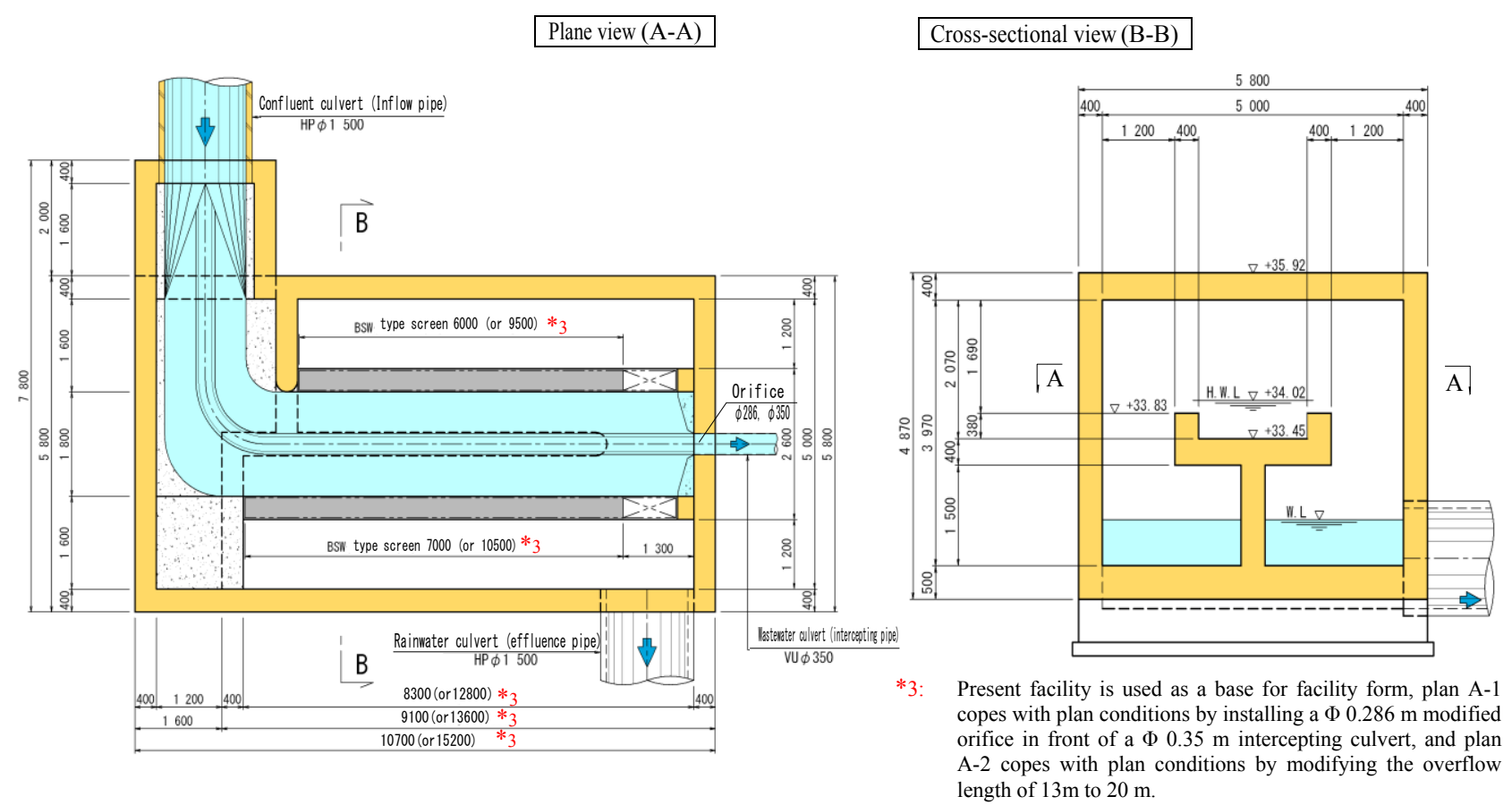

Fig. 9 Schematic view of present facility, improvement plans in conventional technology (Plans A-1and A-2, 1 tank type).

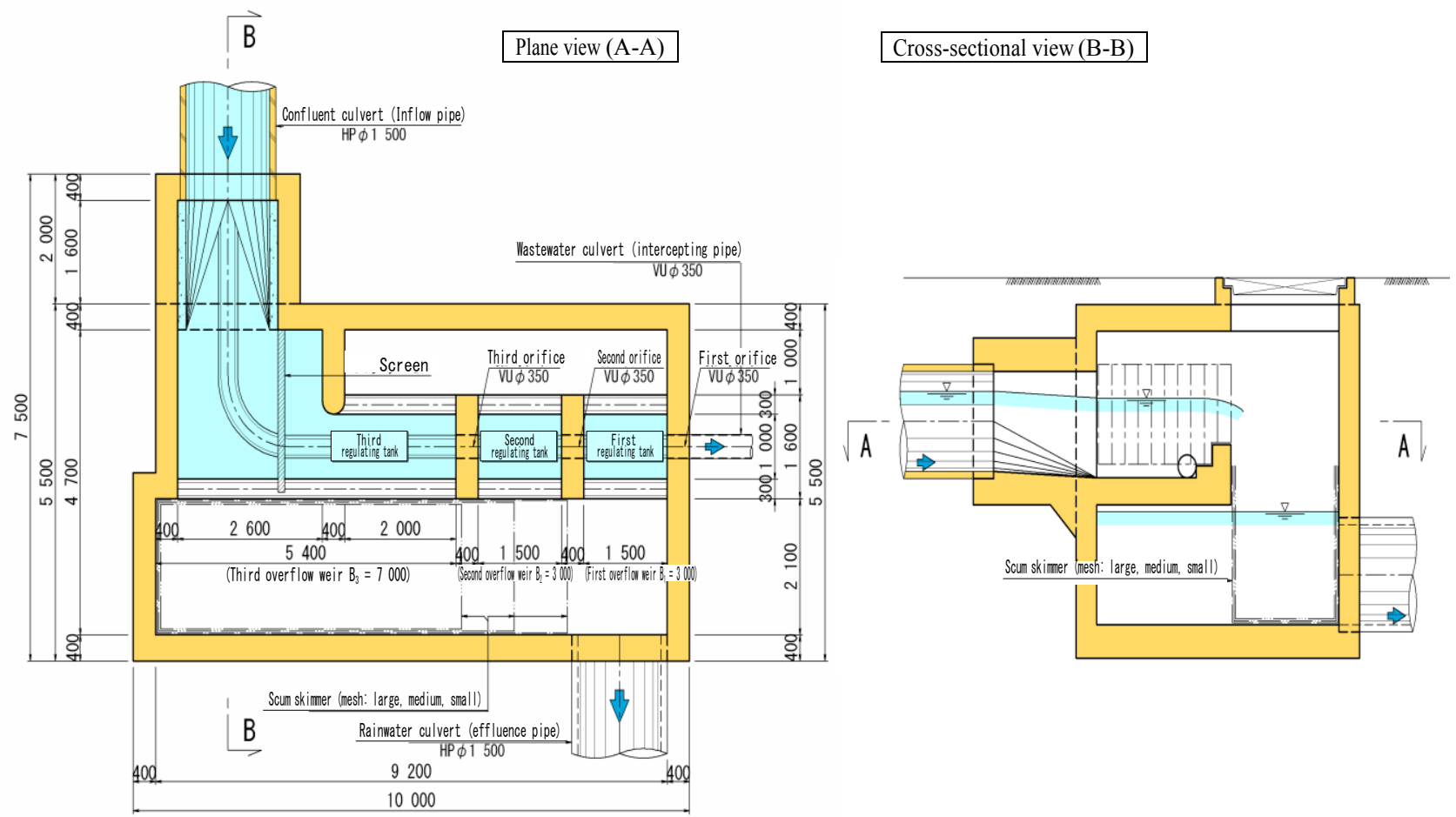

Fig. 10 Schematic view of improvement plan in new technology (Plan B, 3-tanks type).

(3) Numerical analysis and comprehensive evaluation of the intercepting and splitting function

a) Verification of the function of rainwater discharge chamber equipment

For the rainwater discharge chamber improvement plans in Table 5, the numerical analysis results by the calculation method described in Chapter 3 were organized in Fig. 11, and the hydraulic phenomenon under the plan conditions (planned sewage flow rate) was embodied in Fig. 12. Further, verification calculations of the numerical analysis results at the planned sewage flow rate were carried out in Table 6, and matching properties of the planned intercepted sewage flow rate $\left(Q_{0}\right)$ and the intercepted sewage flow rate $\left(Q_{2}\right)$ from the intercepting pipe, the overflow weir flow rate $\left(Q_{1}\right)$ from the effluent pipe, the planned sewage flow rate $\left(Q_{i, \max }=Q_{1}+Q_{2}\right)$ into the inflow pipe, and the interception error were checked. 


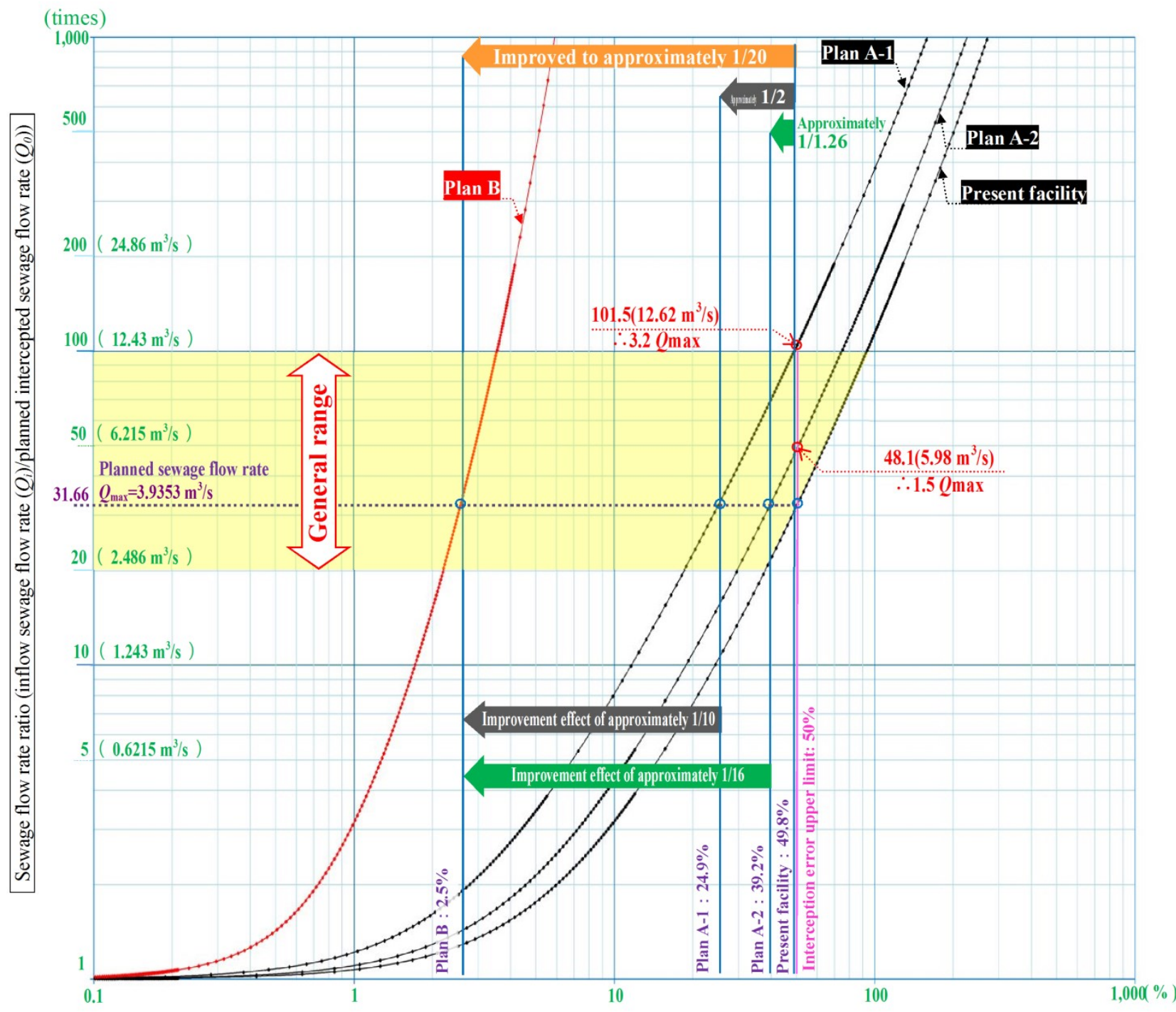

Interception error in intercepted sewage flow rate (excessive intercepted sewage flow rate $\left(Q_{2} \cdot Q_{0}\right)$ planned intercepted sewage flow rate $\left.\left(Q_{0}\right) \times 100\right)$

Fig. 11 Determination chart of interception accuracy by improvement method in project case.

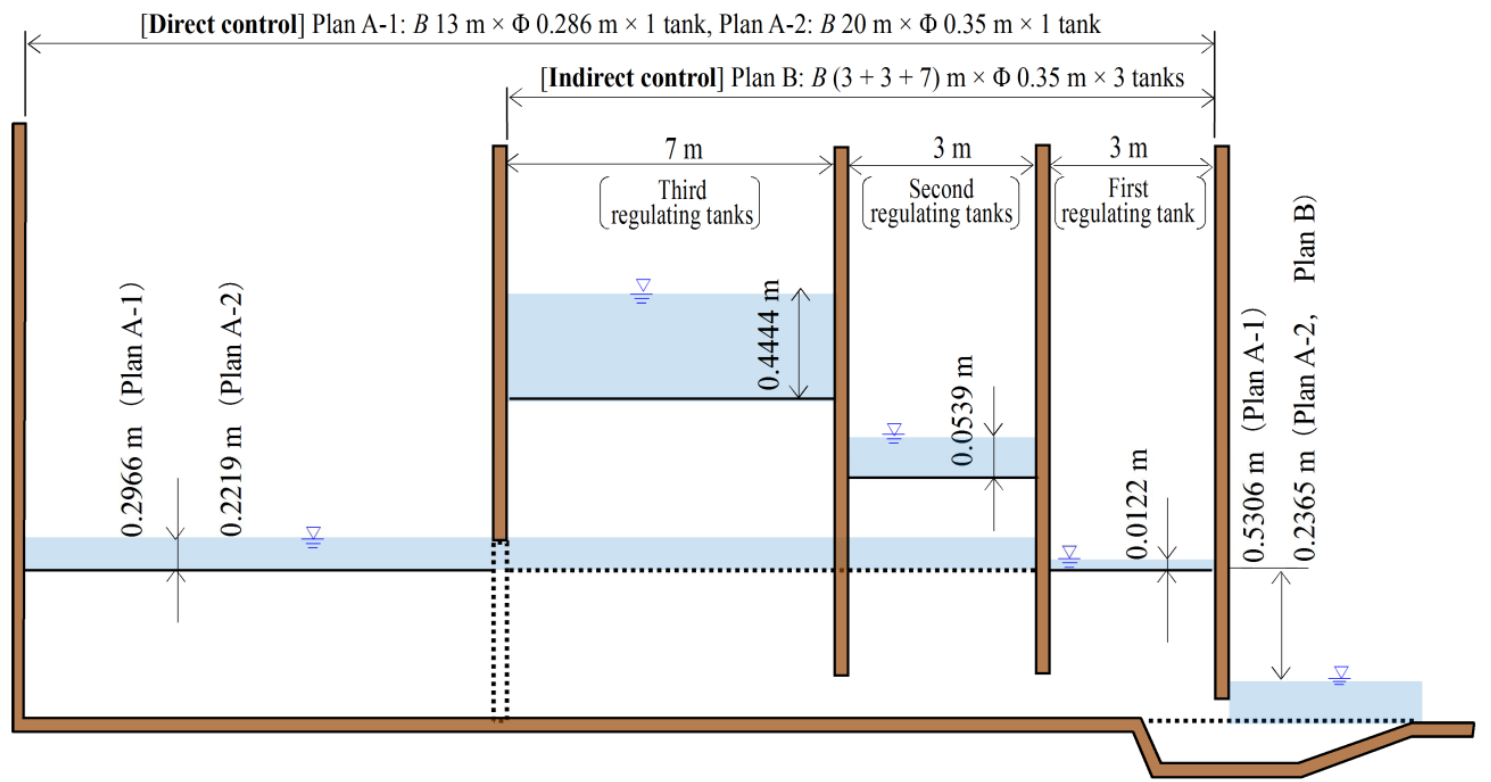

Fig. 12 Schematic view of hydraulic phenomenon in planned sewage flow rate. 
Table 6 Verification table of numerical analysis result.

\begin{tabular}{|c|c|c|c|c|}
\hline & Facility specifications and analysis data & Investigation item and calculation formula & Calculation result & Check and determination \\
\hline & 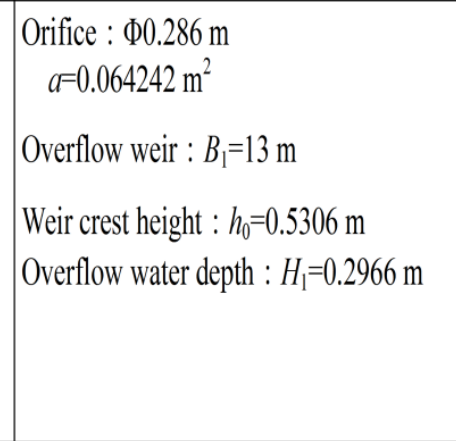 & $\begin{array}{l}\text { Overflow weir height verification } \\
Q_{0}=0.6 \times 0.064242 \times(2 \times 9.8 \times 0.5306)^{1 / 2} \\
\text { Planned sewage flow rate verification } \\
Q_{1}+Q_{2}=1.8 \times 13 \times 0.2966^{3 / 2}+0.6 \\
\times 0.064242 \times\{2 \times 9.8 \times(0.5306+0.2966)\}^{1 / 2} \\
=3.779833+0.155204 \\
\text { Interception error } \\
Q_{2} / Q_{0}=0.155204 / 0.124303=1.2486\end{array}$ & $\begin{array}{l}=3.93504 \mathrm{~m}^{3} / \mathrm{s} \\
\therefore \text { Interception error } 25 \%\end{array}$ & $\begin{array}{l}\cong Q_{\max } \quad \therefore \mathrm{OK} \\
\therefore \text { About } 10 \text { times Plan B }\end{array}$ \\
\hline 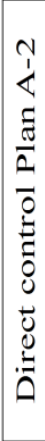 & 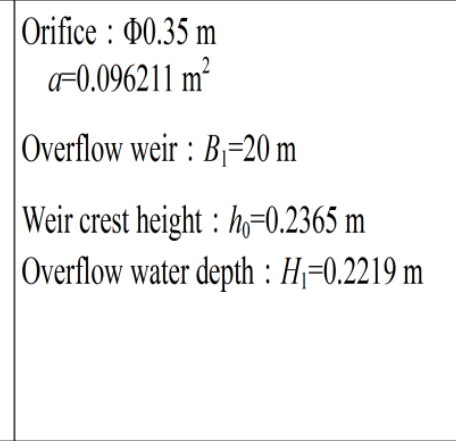 & $\begin{array}{l}\text { Overflow weir height verification } \\
Q_{0}=0.6 \times 0.096211 \times(2 \times 9.8 \times 0.2365)^{1 / 2} \\
\text { Planned sewage flow rate verification } \\
Q_{1}+Q_{2}=1.8 \times 20 \times 0.2219^{3 / 2}+0.6 \\
\times 0.096211 \times\{2 \times 9.8 \times(0.2365+0.2219)\}^{1 / 2} \\
=3.76304+0.17303 \\
\text { Interception error } \\
Q_{2} / Q_{0}=0.17303 / 0.124285=1.3922\end{array}$ & $\begin{array}{l}=3.93607 \mathrm{~m}^{3} / \mathrm{s} \\
\therefore \text { Interception error } 39 \%\end{array}$ & $\begin{array}{l}\cong Q_{\max } \quad \therefore \mathrm{OK} \\
\therefore \text { About } 16 \text { times Plan B }\end{array}$ \\
\hline 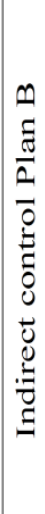 & 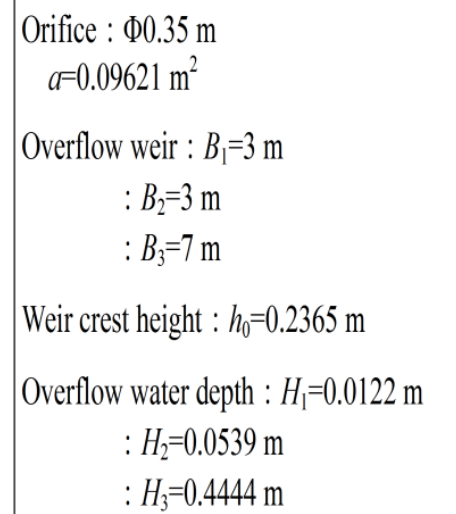 & $\begin{array}{l}\text { Overflow weir height verification } \\
Q_{0}=0.6 \times 0.09621 \times(2 \times 9.8 \times 0.2365)^{1 / 2} \\
\text { Planned sewage flow rate verification } \\
Q_{1}+Q_{2}=1.8 \times\left(3 \times 0.0122^{3 / 2}+3 \times 0.0539^{3 / 2}\right. \\
\left.+7 \times 0.4444^{3 / 2}\right)+0.6 \times 0.09621 \\
\times\{2 \times 9.8 \times(0.2365+0.0122)\}^{12} \\
=3.80762+0.12745 \\
\text { Interception error } \\
Q_{2} / Q_{0}=0.12745 / 0.124285=1.02547\end{array}$ & $\begin{array}{l}=3.93507 \mathrm{~m}^{3} / \mathrm{s} \\
\therefore \text { Interception error } 2.5 \%\end{array}$ & $\cong Q_{\max } \quad \therefore 0 \mathrm{~K}$ \\
\hline
\end{tabular}

\section{b) Comprehensive evaluation of improvement plans}

The improvement plans are evaluated from the viewpoint of the rainwater discharge chamber improvement project including the conventional knowledge, using the intercepting and splitting characteristics and the work outline and so on organized in Table 7.

The improvement effects of the plans similarly, achieve the objective within an expected rainfall which public work project needs to achieve, but the conventional technology (Plans A-1 and A-2) has a narrow response range in an abnormal rainfall for which stability of people's livelihood is intended, and is short of margin of facility function. The indirect control method in the new technology (Plan B) responds even to the abnormal heavy rain with a high intercepting and splitting accuracy and exhibits improvement effect of reliably avoiding the problems in sewage management.

Investment efficiency relates to the difference in skeleton work scale. In particular, Plan A-2 has problems with its expensive elongated dust extractor equipment. Besides, despite having less problems because of employing natural splitting for the function management of the facility, Plan A-1, which throttles the orifice hole, needs to consider dust countermeasure and still has issues depending on the type of the dust extractor.

As described above, the technical evaluation of the new technology (Plan B) is extremely high, but is difficult to employ for public works because of lack of approval from public institutions and lack of actual results of its use. Approval of the technology and production of actual results in the market are big issues in the future deployment of the new technology. 
Table 7 Comparison and investigation table of improvement plans.

$X:$ Inferior, $\Delta:$ Slightly satisfied, $O$ : Satisfied, (): Sufficiently satisfied

\begin{tabular}{|c|c|c|c|c|}
\hline & & Plan A-1 & Plan A-2 & Plan B \\
\hline \multirow{2}{*}{$\begin{array}{l}\text { Improvement } \\
\text { effect }\end{array}$} & $\begin{array}{l}\text { Planned rainfall } \\
\text { scale }(1 / 3 \text { rainfall })\end{array}$ & $\begin{array}{c}\text { Interception error } 25 \% \\
<\text { upper limit } 50 \%\end{array}$ & $\begin{array}{r}\text { Interception error } 39 \% \\
<\text { upper limit } 50 \% \\
0\end{array}$ & $\begin{array}{r}\text { Interception error } 2.5 \% \\
<<\text { upper limit } 50 \%\end{array}$ \\
\hline & $\begin{array}{l}\text { Abnormal rainfall } \\
\text { response }\end{array}$ & $\begin{array}{l}\text { Safe up to } 3.2 \text { times } \\
\text { planned scale rainfall }\end{array}$ & $\begin{array}{l}\text { Safe up to } 1.5 \text { times } \\
\text { planned scale rainfall }\end{array}$ & $\begin{array}{l}\text { No pipe line accident } \\
\text { occurs in any rainfall }\end{array}$ \\
\hline \multirow{3}{*}{$\begin{array}{l}\text { Improvement } \\
\text { investment }\end{array}$} & $\begin{array}{l}\text { Civil engineering } \\
\text { work investment }\end{array}$ & $0.014^{\text {million USS/year }}(94 \%)$ & $0.020^{\text {million US\$/year }}(131 \%)$ & $0.015^{\text {million USS/year }}(100 \%)$ \\
\hline & $\begin{array}{l}\text { Machine and } \\
\text { electrical } \\
\text { equipment } \\
\text { investment } \\
\end{array}$ & $0.095^{\text {million USS/year }}(139 \%)$ & $0.190^{\text {million US\$/year }}(277 \%)$ & $0.068^{\text {million US\$ } / y e a r}(100 \%)$ \\
\hline & $\begin{array}{l}\text { Project investment } \\
\text { scale }\end{array}$ & $0.109^{\text {million US\$ } / \text { year }}(130 \%)$ & $\begin{array}{r}0.211^{\text {million US\$/year }}(250 \%) \\
\times\end{array}$ & $0.084^{\text {million USS/year }}(100 \%)$ \\
\hline \multirow{3}{*}{ Marketability } & $\begin{array}{l}\text { Equipment } \\
\text { function } \\
\text { management }\end{array}$ & $\begin{array}{l}\text { Highly reliable } \\
\text { because of natural } \\
\text { splitting }\end{array}$ & Same as left & Same as left \\
\hline & $\begin{array}{l}\text { Technical } \\
\text { approval/actual } \\
\text { result }\end{array}$ & Many & Same as left & $\begin{array}{l}\text { No approval and actual } \\
\text { result } \\
\times\end{array}$ \\
\hline & $\begin{array}{l}\text { Sewage } \\
\text { management/expa } \\
\text { ndability }\end{array}$ & $\begin{array}{l}\text { Low reliability and } \\
\text { limited expandability } \\
\times\end{array}$ & Same as left & $\begin{array}{l}\text { High reliability and } \\
\text { high expandability } * 4\end{array}$ \\
\hline
\end{tabular}

*4: Lead to improvement of whole system of combined sewer system. Refer to Chapter 6(2).

\section{CONCLUSION}

\section{(1) Study background and results of the new technology}

This study has constructed a new theory of the flowing water splitting function of the rainwater discharge chamber using the conventional hydraulic knowledge and verified its practicality through numerical analysis and hydraulic model experiment.

The flowing water splitting theory organically combines the hydraulic characteristics of an overflow weir and an orifice, and includes the conventional method of directly controlling the target flow rate and the new technical method of indirectly controlling the target flow rate by water surface regulation.

The results of the numerical analysis to calculate the interception error showed that the method of the new technology (three regulating tanks) exhibited improvement effect as high as about 40 times that of the conventional technology (one regulating tank). In the hydraulic model experimental results, the indirect method of the latter technology also exhibited improvement effect as high as about 15 times that of the direct control of the former technology. The cause of the difference in improvement effect existed in the setting of the flow rate coefficient in the numerical analysis, the limit of the measurement accuracy of the hydraulic model experiment and the like. The improvement effect was determined to be close to the numerical analysis result on a site where the target flow rate was large, and therefore the indirect control method of the new technology was accepted to be safe in terms of sewer management. In the reproduction verification of the project case, the superiority of the indirect control method of the new technology in terms of improvement and investment, was confirmed.

\section{(2) Present effects and prospects of the new technology}

The rainwater discharge chamber function of the new technology ensures that the sewage management of the combined sewer system is highly reasonable and greatly contributes to the solution of present issues, which are the objectives of the combined sewer improvement project. Note that a reliable sewage management system enables time-series control of sewage management through the same target flow rate retention as that of flood prevention in the river project. It significantly rationalizes expensive and complicated operation of supplemen- 
tary machine and electric equipment systems in facility management with a simple and inexpensive civil engineering system. The same effect obtained in the whole area of the basin-wide sewerage system will benefit city areas, as well as developing countries in the future.

\section{REFERENCES}

1) Japan Sewage Works Association: Guidelines for Sewage Planning and Design and Instructions, pp. 106-119, 259-262, 2010.1 (in Japanese).

2) Japan Institute of Wastewater Engineering and Technology: Combined Sewer Improvement Measure Filtering Screen Technical Manual, pp. 7-13, 2003.3 (in Japanese).

3) Japan Sewage Works Association: Combined Sewage Improvement Measure Guideline and Explanation, pp. 122-123, 153-161, 163, 2002.6 (in Japanese)

4) Sewerage and Waste Water Management Department of the City and Region Development Bureau in the Ministry of Land, Infrastructure and Transport: SPIRIT 21 Practical Use of Eight Technologies for Combined Sewerage Improvement, 2004.6 (in Japanese).

5) Japan River: Anti-disaster Reservoir Technical Standard (draft), pp. 85-92, 2002.10 (in Japanese).
ACKNOWLEDGMENT: This study is an industry-college cooperative study, and the authors wish to express their sincere thanks to persons in charge of the actual operation of the sewer projects who have given effective suggestions to the authors in accomplishing this study.

6) Japan Sewage Works Association: Sewage Rainwater Regulating Reservoir Technical Standard (draft), pp. 18-19, 2007.3 (in Japanese).

7) Tsubaki, T. and Araki, M.: Hydraulic Exercise (Vol. 1), pp. 197-208, Morikita Publishing, 1978.3.

8) Homma, M. and Aki, K.: Mononobe Hydraulics, pp. 190-199, Iwanami Shoten, 1962.7 (in Japanese).

9) Sewage Bureau of the Tokyo Metropolitan Government: Combined Sewer Improvement in Tokyo, http://www.gesui.metro.tokyo.jp/oshi/infn0765/siryou_076 5.pdf

10) Construction Bureau of the Tokyo Metropolitan Government: Final Report of Future Construction of Small and Medium-sized Rivers in Tokyo, pp. 6-7, 2012.11 (in Japanese).

(Received July 12, 2016) 